\title{
Time for Climate Change: Leadership, IT Climate, and Their Impact on Organizational Performance
}

\author{
Nico Wunderlich \\ Goethe University Frankfurt / E-Finance Lab \\ nwunderlich@wiwi.uni-frankfurt.de
}

\begin{abstract}
Information systems (IS) have become essential for operating firms successfully. How to align business and information technology (IT) executives to increase organizational output has been widely discussed in literature. This research focusses on prerequisites and consequences of a positive IT climate in organizations where the need for deep IT and business knowledge is constantly increasing. We shed light on how organizational leaders, both from business and IT, influence a positive organizational IT climate by IT leadership and subsequently, how an organizational IT climate affects strategic alignment and firm performance. By applying a two steps approach, this study evaluates the results of a survey among 322 IT decision makers in the U.S. working in knowledge-intensive and less-knowledge intensive industries. Our findings illustrate that IT leadership and IT climate differ between the two groups, and can confirm organization wide firm IS knowledge as a strategically important resource to achieve organizational performance.
\end{abstract}

\section{Introduction}

At latest with the turn of the millennium and the rise of the Internet economy, it became evident that organizations have to take knowledge and capabilities management as well as their IS more seriously to stay competitive. While each of those realms are well understood separately [43], their interplay within an organization and the transmission process towards successful strategic business IT alignment for performance is still not completely explained. Knowledge and IT-intensive business processes became the foundation of value generation in developed countries, where three-fourth of the gross domestic productivity is now based on knowledge and ITintensive activities [61]. This requires that the IT and business leaders come together and form a common understanding of the functions, knowledge, and capabilities of each other as precondition of a functioning strategic IT business alignment [37]. However,

\author{
Roman Beck \\ IT University of Copenhagen \\ romb@itu.dk
}

that means that the business and IT side of the management has to jointly develop an informed, appreciative IT climate among the workforce, since otherwise it will be difficult to implement a positive IT and knowledge sharing culture [48]. This is especially true when considering that strategic IT alignment can be regarded as the product of successful organizational knowledge integration, which in turn is triggered by strategic decision making [33, 32]. Social IT alignment in IS research recently concentrates on complex networks and how socio-organizational structures enforce IT alignment [47, 32, 46], while there is evidence that informal, cultural structural elements embedded in organizations which we coin IT climate is crucial for successful IT alignment [50].

The challenge is how to create an IT climate in an organization where IT is increasingly penetrating all kinds of knowledge-intensive business areas [49]. Based upon, the top management is in charge of and "installs" the IT climate through leadership practices that influence organizational climate as stepping stone towards organizational outcome [62]. In the same line of argument, a strong IT leadership position is essential to establish IT capabilities and practices for effectively utilizing IT in knowledgeintensive business processes [11]. In this research, we address the aforementioned challenges by focusing on organizational climate and IT mindset and answer the call for more research on the influence of practices, interpretations, and beliefs as parts of organizational climate on strategic alignment [50]. We furthermore shed light on how top management from the business and IT side influence the IT climate as it has been proposed by qualitative research [62] to give first insights on implementing an organization-wide IT climate. Thus, we propose two overarching research questions:

RQ1: What is the role of top management leadership in influencing a positive organizational IT climate and which consequences do these prerequisites have on strategic alignment and firm performance?

RQ2: Which effects can be observed to the aforementioned interrelations in regards to knowledge and IT intensity of different industries? 


\section{Literature Background}

\subsection{Strategic Alignment}

Aiming for a homogeneous interaction between strategies, processes, and infrastructures between the business and IT side in an organization, the strategic alignment model (SAM) was conceptualized [28]. In our research, we concentrate on the intellectual alignment of business and IT strategy in SAM as commonly referred to as strategic alignment [47, 32], which can be rooted back to its defining elements in business and IS strategy [54]. Grounded on SAM, the contradictory discourse about the effect of IT alignment on firm performance was dissolved in recent research through the introduction of positive IT influence construct [25]. For the impact of strategic alignment on firm performance, we built upon prior research demonstrating that there is a positive impact [10, 63, 32, 54].

Investigating how to achieve this strategic conformance in an organization, IS research analyzed extensively the mental alignment between the involved top management executives of the business and IT functions in two dimensions: on a structural and cognitive level (e.g., structural systems of knowing, shared understanding, educational mechanisms $[47,51,3])$, as well as on social and communication related level (e.g., social systems of knowledge, shared language, relational similarity [47, 52, 3]). Deriving from these mechanisms, we position shared domain knowledge as predecessor for strategic alignment $[52,10]$. Overcoming the divide of business and IT, a shared vision of IS within an organization turns out to be an indicator for successful relationships between the organization's leaders $[12,21$, $47,3]$.

\subsection{Organizational Climate}

Organizational climate comprises the shared perceptions of practices and procedures of a work environment [31]. Closely related to the concept of organizational culture, organizational climates prescribe the transformation of the rather permanent and enduring cultures into behavioral and attitudinal mindsets [62, $31,20]$. Organizational cultures are defined as shared sets of common values, understandings, and beliefs [30, 55]. Developed by Lewin in 1947 [36], recent research on the concept of organizational climate concentrates on intangible organizational facets such as vision, learning, and empowerment, extended by examining the impact on organizational outcomes [62]. Organizational leadership impacts the perceptions of organizational climate [31]: The behaviors of the leaders in setting policies, roles, and legitimizing managerial decisions create the organizational climate on how employees perceive and interpret the leaders' actions [19]. Consequently, there is indication that leadership practices influence organizational climate and subsequently organizational outcomes [62]. Watt and Henderson [62] also proposed the concept of IT climate within an organization in their qualitative research, emphasizing particularly the role of chief information officer (CIO) practices as the highest-rank IT leader on IT organizational climate. In previous research, this has been investigated only once before as "IT management climate" [8]. Few studies coped with the design of an IT climate focused on knowledge exchange, but it has been stated that IT climate has a positive impact on managerial IT knowledge [8]. Furthermore, organizational cultures were found to influence the socially related dimensions of alignment as well as the perception and response in the context of IS implementation [50].

\subsection{Organizational Knowledge}

In modern knowledge-intensive industries with their highly specialized disciplines and global value generation footprint, knowledge is more than ever a pivotal company resource $[7,43,61]$ and, thus, object of interest of how knowledge can be gained, disseminated, and valued within organizations [40]. „Knowledge is essentially related to human action“" [60], p.974]: In the first instance, individuals create new and store existing knowledge, while subsequently, organizations are critical as institutions to integrate, articulate, and augment this knowledge [40]. The continuous exchange and combination of tacit and explicit knowledge creates organizational knowledge [40]. Describing the assemblage of collective understandings in an organization [60], organizational knowledge is instrumental to achieve competitive advantage by deploying organizational resources [7]. Consequently, one can view an organization as a vital, connected network of organizational knowledge about, e.g., values, rules, and justifications, which underlines the relevance of work-related shared understandings [60].

Organizational climates enhance knowledge flows in firms [15] through organizational cultures which impact knowledge creation and sharing [1]. According to the declared influence of leadership on organizational climates, theoretical and empirical deliverables constitute the contribution of leadership towards sharing, creation, and collecting of knowledge [35], for instance, the legitimization of knowledge leaders by top management support [1]. The concept of organizational knowledge creation advises leaders as synergists to simulate the transformation of knowledge [40] while cognitive processes taking 
place in work-related social processes between leader and followers serve as a reasonable rationale to explain a group's capacity to engage in organizational knowledge creation [35].

\subsection{Knowledge Intensity}

Commonly, IS workflows and initiatives are stated as knowledge-intensive and demand specialist IT skills to cope with technical issues [34]. Appropriate support by the IT function is a way to effectively utilize IS by end users $[49,18]$. Therefore, skills like business knowledge as well as inter-disciplinary interaction are crucial to IS personnel [34]. Recent studies examine how mission-critical knowledge can be effectively transferred to end users through IS support in IS post-implementation stages $[18,56]$. By translating this understanding into common practices, organizations become capable in developing competencies for deploying their resources effectively [49]. Especially in knowledge-intensive organizations, focusing on organizational knowledge is key to strategic and managerial considerations, decisions, and activities, as knowledge is the primary resource to constitute core competencies [16,59]. Value creation of today's products derives primarily from the development and management of intangible intellectual resources [61]. Studies in knowledge-intensive industries find high necessity and potential for organizational learning from hierarchical exposed senior managers as central source of knowledge [58]. Between the year 2000 to 2011, within the OECD member countries a concentration in knowledgeintensive service sectors had been observed by an increase of the share of employees in these industries account of the manufacturing sectors [42].

\section{Research Model and Hypotheses}

In our research we shed light on the interrelations between CIO leadership, the creation of an IT climate and its influence on strategic alignment (figure 1). As knowledge is the central resource to build up IT competencies and capabilities to deploy the IT resources effectively [43], we affirm the degree of already disseminated IT knowledge on different hierarchical levels throughout the organization as effected by the extent of an established organizational IT climate [8]. The congruence of leadership to both the constructs of IT climate and knowledge dissemination maintain the central basis and linkage of this investigation $[40,35,31]$. Thus, we concentrate on a strategic and descriptive perspective while operational and prescriptive aspects, for example knowledge management practices, are topic to further investiga- tion. The aim of this research is to observe organizational constellations and preconditions for embedding an organization-wide IT climate to overcome the organizational borders of the IT function and extend its cross-linking throughout the whole organization.

Alongside with the growing emphasis of IT on strategic targets and business outcome, the responsibility of the CIO as IT leader [4] in developing and implementing appropriate IS increases [34]. Establishing essential skills, competencies, and capacities in this area is defined as IT capability management and key responsibility of the CIO aiming at delivering value from IT investments by effectively exploiting IT infrastructure [43]. Reflecting this increased importance of IT to organizations, the hierarchical rank of the IT executive has a positive impact on the success of IT initiatives [4]. Since the CIO is part of the board, additional competencies in communication are of importance $[52,47]$. The CIO's ability to transfer value-creating knowledge and relevant insights on IT to top management colleagues such as the CEO depends on the formal and informal interplay between these organizational leaders [3] and refers to the concept of social alignment [47]. Further, a shared vision of IT between business and IT managers in an organization builds on adequate IT knowledge of the top management team (TMT) [43]. Leadership as a dimension of organizational climate is supposed to influence organizational knowledge creation [31], whereas IT knowledge of managers increases with access to relevant sources such as IT experts inside the organization [6]. Consequently, we state:

H1: CIO Leadership has a positive impact on TMT strategic IT knowledge.

Figure 1. Research Model

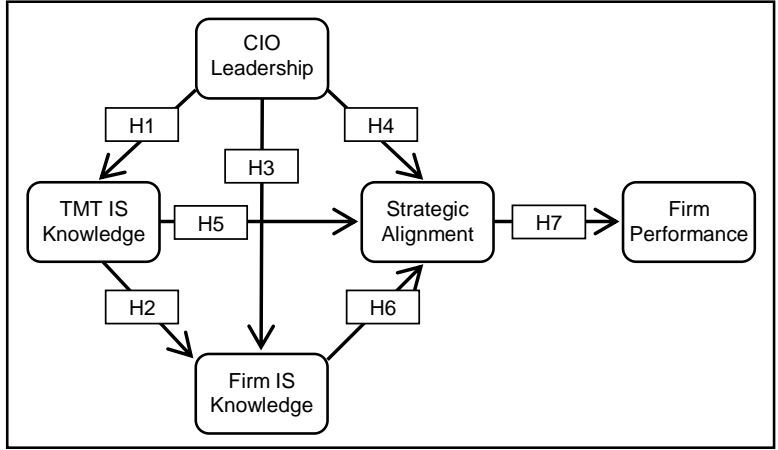

Creating benefits out of IS, employees as IT-users in an organization should be capable in using a system with a certain extent and effectivity [18]. Inevitable to IT skills is IT knowledge, being stored and applied by employees $[49,43,38]$. We extend the perspective on essential strategic business IT knowledge to business personnel [56]. In line with the proposed 
relation between IT leadership and knowledge sharing to develop an organizational IT climate [35], here, we concentrate on the importance of the general top management to lead knowledge dissemination in organizations [1]. Thus, we hypothesize the following:

H2: TMT IT knowledge has a positive impact on firm IT knowledge.

Based on the growing importance of IT for business processes [49], regarding all employees within an organization as the "IT team" seems to be adequate. The positive effect of IT knowledge middle managers possesses could be transferred to each employee [3]. The TMT also gives legitimacy to the $\mathrm{CIO}$ as knowledge leader [1]. The higher the structural power of the CIO, the higher the perceived strategic decision-making authority of the IT leader [46]. According to Mintzberg [39], the role of a leader comprises motivating and guiding of subordinated followers. CIOs create and facilitate an appropriate IT climate within an organization thereby supporting effectively the sharing of IT knowledge [8]. We propose:

H3: CIO leadership has a positive impact on firm IT knowledge.

Organizational cultures are expected to influence a firm's alignment processes [50]. Referring to the close relation of organizational cultures and climates $[62,31]$, the following three hypotheses comprehend the supposed influence of an established IT climate on strategic alignment. Central to strategic alignment is a "shared view" among the organization's top decision makers about the role of IS within the organization [12]. Further, the CIO's authority in decision making has a significant impact on the ability of IT to contribute to strategic IT alignment [46]. Likewise, we propose:

H4: CIO Leadership has a positive impact on strategic alignment.

Business managers IT knowledge is highly correlated with their IT experience, both parameters influence the business managers' intentions to support IT initiatives valuing the role of IT for enterprise profits [6]. Shared IT knowledge between IT managers and business managers leads to an enhancement of strategic alignment $[33,10]$. More precisely, mediated by shared understanding, TMT IT knowledge leads to strategic alignment [47]:

H5: TMT IT knowledge has a positive impact on strategic alignment.

According to literature, organizational support describes an organization's willingness to contribute to IT initiatives [46, 13]. Both IT and business competencies jointly lead to strategic capabilities alignment [17]. Capabilities are based on suitable knowledge
[43]. As IT and business units share the responsibility for IT alignment [52], we propose:

H6: Firm IT knowledge has a positive impact on strategic alignment.

Alignment leads to effective deployment of IT resources and consequently competitive advantage [33]. Besides the well accepted and empirically evident positive impact of strategic alignment on firm performance $[10,32]$, to our investigation possible indirect effects of knowledge and leadership on organizational output are of interest as well. To the first, knowledge exchange and combination leads to higher firm performance [15]. The latter, IT climate is supposed to influence organizational outcome as well [62]. Thus, we hypothesize:

H7: Strategic alignment has a positive impact on firm performance.

\section{Data Collection and Research Analysis}

\subsection{Data Preparation and Survey Sample}

In order to test and validate the presented hypotheses and the proposed research model as illustrated in figure 1 , we conducted a quantitative survey among senior IT decision makers in the U.S.. Participants of a CIO panel operated by a large international market research institute were asked to join in the online survey during August and September 2015, resulting in $\mathrm{N}=322$ complete questionnaires. We initiated the survey on our behalf and hosted it on our own online survey server. With regard to the set of research questions, we considered only IT decision makers from companies with more than 100 employees and with IT departments of at least two employees. Due to the online panel interview procedure, no discontinuation was observed. Respectively, we implemented several interventions to ensure the appropriate quality of data, e.g., track questions as well as plausibility checks for consistent answers. As a result, we eliminated 30 respondents from the gathered data.

\begin{tabular}{|c|c|c|c|c|c|}
\hline \multicolumn{6}{|c|}{ Table 1. ClO characteristics } \\
\hline \multicolumn{2}{|c|}{ Gender } & \multicolumn{4}{|c|}{ Age } \\
\hline Male & Female & $20-25$ & 8 & $46-55$ & 90 \\
\hline 203 & 119 & $26-35$ & 59 & $56-65$ & 41 \\
\hline $63 \%$ & $37 \%$ & $36-45$ & 118 & $66-75$ & 6 \\
\hline \multicolumn{6}{|c|}{ Job Position } \\
\hline \multicolumn{4}{|c|}{$\mathrm{CIO}$ / vice president IT, CTO, CSO } & 129 & $40.1 \%$ \\
\hline \multicolumn{4}{|c|}{$\begin{array}{l}\text { director of systems development, } \\
\text { director of IT/IS operations, internet } \\
\text { technology strategist }\end{array}$} & 127 & $39.4 \%$ \\
\hline \multicolumn{4}{|c|}{ other IT decision makers } & 66 & $20.5 \%$ \\
\hline
\end{tabular}


Table 1 describes the final data set. The attributes of the respondents were measured by means of the elaborately compiled scale of Aral and Weill [2]. The average organizational tenure of IT leaders of 11.8 years indicates a rather senior IT decision maker sample $[2,38]$, corresponding with a high professional IT experience of 15.4 years on average. Analyzing firm characteristics, the average firm in our sample was founded in 1968, has 10.920 employees and an IT department employing 740 IT experts. The sample includes 40 of the 50 States of the U.S. Summing up, the sample provides an adequate view on firms and CIOs in the U.S. and holds for further analysis.

\subsection{Operationalization of Constructs}

All measures are based on constructs that have been published in one of the AIS senior scholar basket journals. We consciously stayed as close as possible to the original operationalization to keep our results comparable to former studies. Thus, all items where adopted from original sources, while all modifications are presented in table 2 for transparency reasons. All items will be discussed in the following. The scale of TMT strategic IT knowledge was taken from a study investigating social antecedents of strategic alignment [47]. Originally formulated by [3], the items cover TMT knowledge on current and future IS as well as a reflection of market oriented IS knowledge. The measuring instrument of firm strategic IT knowledge was newly developed, based on the aforementioned scale of TMT strategic IT knowledge [47]. An organization's ability to outperform its core competencies is likely dependent on its IT capabilities, whereas IT capabilities are commonly restricted to the routines of the IS department [49]. Through this new construct of firm strategic IT knowledge, we cover the organization-wide extension of these capabilities, emphasizing IT knowledge of business personnel as progressively essential.

Organizational outcomes of organizational climates are influenced by the leadership practices on framing vision, strategy, policies, and acting on legitimized empowerment [62, 19, 31]. Creating and establishing an inspiring vision of IT for an organization is a CIO's demonstration of acting strategically effective [46]. Implementing a sustainable strategy for IT is a valuably procedure to integrating business demands in IT leadership [38]. Issuing policies and guidelines is one of the ethical elements constituted by leaders determining organizational climate [19]. The amount of IT budget is closely related to organizational support for IT [21]. To capture the actual executed leadership of the CIO properly, we build upon a CIO leadership construct from a study on business competence of IT professionals [5], conceptualizing the CIO leadership items by modification of a set of items which originally measured business managers' experience in general management [6]. Thereby, we are able to transform an existing and well developed construct including the sought leadership items of setting IT vision, strategy, policies and budget.

\begin{tabular}{|c|}
\hline Table 2. Modified Measurement Items \\
\hline $\begin{array}{l}\text { All measured on } 5 \text {-point Likert scale: } 1=\text { not well } \\
\text { informed, } 5=\text { extremely well informed }\end{array}$ \\
\hline CIO Leadership (modified from [6]) \\
\hline $\begin{array}{l}\text { I lead or participate in creating an IT vision state- } \\
\text { ment regarding how IT contributes to business val- } \\
\text { ue and strategy. }\end{array}$ \\
\hline I lead or participate in developing IT strategy. \\
\hline I lead or participate in creating IT policies. \\
\hline I lead or participate in setting IT budgets. \\
\hline $\begin{array}{l}\text { Firm IT knowledge (modified from [47]; original } \\
\text { scale: TMT IT knowledge) }\end{array}$ \\
\hline $\begin{array}{l}\text { How knowledgeable are the employees of your } \\
\text { company about the potential and limitations of cur- } \\
\text { rent IT? }\end{array}$ \\
\hline $\begin{array}{l}\text { How knowledgeable are the employees of your } \\
\text { company about the potential and the limitations of } \\
\text { "next-generation" IT? }\end{array}$ \\
\hline $\begin{array}{l}\text { How knowledgeable are the employees of your } \\
\text { company about your competitors are applying IT? }\end{array}$ \\
\hline
\end{tabular}

We measure IT alignment as strategic alignment and conceptualized it based on two prior studies on the influence of socially predetermining factors of IT alignment [47, 32]. Firm performance was evaluated by the respondents during the online survey as well, captured by market oriented and competition sensitive parameters such as market share and sales per year, both relating to the year of 2014 .

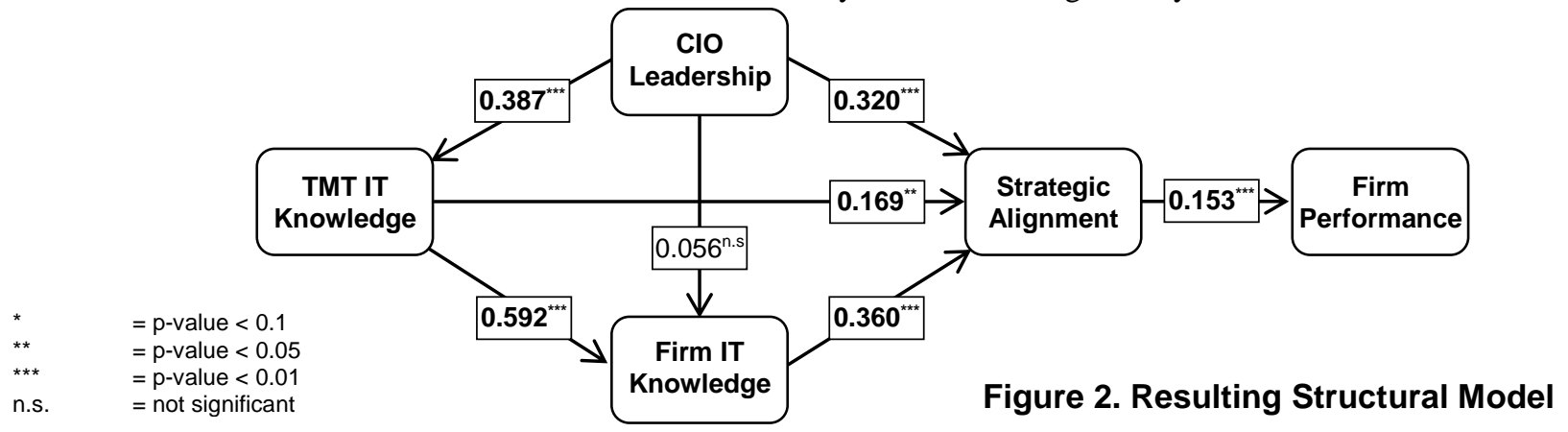




\subsection{Measurement Model Validation}

Initially, the measurement model consisted of five reflective constructs. As primary stage to analyzing the path relations, we pursue several tests on the reflective measurement constructs for reliability, convergent validity, and discriminant validity. For construct reliability, we evaluated the average variance extracted (AVE) and the composite reliability (CR) (table 3). The calculated values surmount the proposed threshold of 0.5 for AVE [14] and 0.7 for CR. Additionally, we scored Cronbach's alpha for all constructs except for one above the desirable minimum alpha of 0.7 [41] and moreover three clearly above the higher threshold of 0.8 . By having a closer analysis of firm performance, we identified a high dependence of Cronbach's alpha on the number of items as one possible reason for the weak performance. Finding the values for AVE and CR above the recommended thresholds as well as crossloadings on other constructs low, we accept it as a minor issue and keep the reliability of this construct in mind for the further course of this analysis. In a further step, discriminant validity was assessed by computing the inter-correlations between the latent variables according to the Fornell and Larcker criterion [22]. We found the AVE of each construct as higher than the square root of the correlation to every other construct [23]. Thus, we found evidence suggesting a suitable reliability as well as convergent and discriminant validity scores.

\section{Table 3. Reliability, Validity, Determination}

\begin{tabular}{|c|c|c|c|c|}
\hline Construct & AVE & CR & Alpha & $\mathbf{R}^{\mathbf{2}}$ \\
\hline $\begin{array}{c}\text { CIO } \\
\text { Leadership }\end{array}$ & 0.644 & 0.878 & 0.816 & - \\
\hline $\begin{array}{c}\text { TMT IT } \\
\text { Knowledge }\end{array}$ & 0.794 & 0.920 & 0.870 & 0.150 \\
\hline $\begin{array}{c}\text { Firm IT } \\
\text { Knowledge }\end{array}$ & 0.778 & 0.913 & 0.858 & 0.379 \\
\hline $\begin{array}{c}\text { Strategic } \\
\text { Alignment }\end{array}$ & 0.661 & 0.854 & 0.744 & 0.443 \\
\hline $\begin{array}{c}\text { Firm } \\
\text { Performance }\end{array}$ & 0.550 & 0.702 & 0.200 & 0.023 \\
\hline $\begin{array}{c}\text { AVE = Average Variance Extracted, Alpha = Cronbach's } \\
\text { alpha, CR = Composite Reliability, R }=\text { C.of determination }\end{array}$ \\
\hline
\end{tabular}

To test the proposed hypotheses, we conducted a data analysis based on a structural equation model (SEM) using SmartPLS v.3.2.3 as software tool [53]. The test results are displayed in figure 2. The research model for the full sample calculated employing a components based approach with a 500 sample bootstrapping technique for model assessment [14]. In general, comprehensive relationships between latent variables are provided by SEM [9]. This technique provides simultaneous computation while modeling relationships between multiple independent and de- pendent constructs [24]. Based on the described data set of 322 respondents, the $\mathrm{R}^{2}$ values (table 3 ) of strategic alignment $(0.433)$ as well as for the newly calibrated firm IS knowledge construct (0.379) indicate strong amount of variance explained [14], as for TMT IS knowledge moderate effect $(0.15)$. The weak but acceptable effect of firm performance (higher than 0.02) corresponds to the discussed lower reliability of this construct within the collected data. Reviewing the relevant p-values (figure 2), six of the seven proposed hypotheses finally support derivation for statistically definite conclusions. Moreover, five hypotheses could be confirmed at highly significant 0.01 level. One we found only significant at $\mathrm{p}<0.05$ level (H5), while H3 had to be rejected ( $>>0.10)$, both due to mediation effects.

According to the prescribed procedures based on distribution independent bootstrapping results [27, 45], we conducted a mediation analysis of all possible additional connections going beyond the disposed hypothesized relations. Hence, $\mathrm{H} 3$ is fully mediated by TMT IS knowledge. H5 is partially mediated by Firm IS knowledge. Strategic alignment partially mediates the influence of TMT IT knowledge on firm performance. Moreover, no other mediation effects could be found for strategic alignment, which states IT alignment as necessary to explain the impact of the CIO and the business IT knowledge on firm performance. We will integrate this diagnosis into results discussion. Additionally, for evaluating the explanatory power of the dependent variables strategic alignment and firm performance, we controlled for firm size, firm age, industry sector, number of employees of the IT department, and state. Only firm size and the number of IT professionals have marginal effects on both constructs just around the medium threshold of $p=0.05$. These effects are reasonable and weak enough not to pursue. To check for common method bias, we applied the Harman single factor test verifying no more that $50 \%$ of the total variance of all items to be explained by a single component [44].

\subsection{Multigroup Analysis}

To deeper investigate the relevance of knowledge for strategic outcomes, we conducted a group comparison between knowledge-intensive and less knowledge-intensive organizations. The OECD provides a clustering of industries grouped upon the degree of knowledge intensity, which can be found interdependent with a high amount of investments in IT [42]. Reportedly, knowledge-intensive industries were subdivided into two types: first, industrial enterprises domiciled in the manufacturing as well as biotechnology sector, and second, knowledgeintensive services, namely finance, communications, 
legal, accounting, etc., complemented by the "nonmarket" high level knowledge services education and medical. Table 4 shows how these categorizations outperform in our sample. A remarkable difference turns out on the average size of the IT department, namely from 405 IT professionals in none knowledge-intensive firms to 740 in knowledgeintensive industries: Knowledge intensive enterprises maintain larger IT functions.

\begin{tabular}{|l|c|}
\hline \multicolumn{2}{|c|}{ Table 4. Industry Sector } \\
\hline \hline Knowledge-intensive industries & $\mathbf{n = 2 0 4}$ \\
\hline \hline Computer (Hardware, Software, Services) & 36 \\
\hline Banking, Financial Services, Insurance & 31 \\
\hline Industrial Manufacturing & 25 \\
\hline Healthcare, Medical & 22 \\
\hline Education, Training & 20 \\
\hline Advertising, Consulting, Market Research & 19 \\
\hline Aerospace, Automotive, Defense & 17 \\
\hline Other knowledge-intensive industries & 34 \\
\hline Non knowledge-intensive industries & $\mathbf{n = 1 1 8}$ \\
\hline \hline Retail & 25 \\
\hline Business Services (Staffing, Printing, etc.) & 24 \\
\hline Transport, Transportation Services, & 18 \\
\hline Logistics, Travel, Tourism, Hospitality & 10 \\
\hline Energy, Utilities, Oil, Gas, Metals, Mining & 9 \\
\hline Construction (Contractor, Home Builder,..) & 9 \\
\hline Other non knowledge-intensive industries & 32 \\
\hline
\end{tabular}

The rationale for conducting a group comparison derive from the huge heterogeneity between at least two groups of respondents [27]. To test the differences between the two groups, we used the PLS multigroup analysis [29] to estimate by non-parametric significance test if the proposed deviations in some path relations differ significantly. We followed a calculation approach provided in SmartPLS 3 [53] conducting the multigroup bootstrapping technique on the basis of 5.000 subsamples and a two-tailed bootstrapping test type on a significance level of 0.05 [57].

It turns out that the influence of TMT IS knowledge on firm IS knowledge is significantly higher in knowledge-intensive industries (figure 3). Likewise, the relation of CIO leadership to strategic alignment differs significantly between the two subsamples. Three connections turn out to be insignificant, by deviation of the path coefficient of zero between the groups meaning an equal impact of this relation in the full sample (H1, H6, H7). The medium significant differences will not be interpreted as their meaning stays unclear. A difference between the groups might be higher than the path coefficient for the entire sample due to higher coefficients in one group without becoming negative in the opposite group.

Figure 3. Multigroup Differences

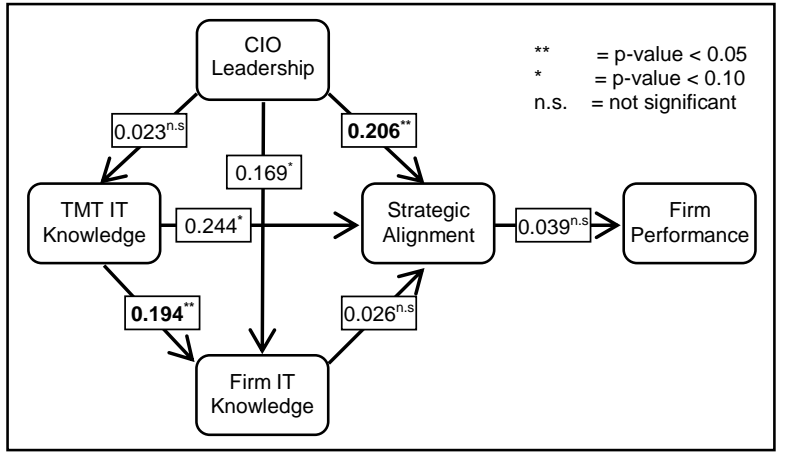

\section{Results and Discussion}

In this study, we were able to clarify the agency of business and IT leaders in influencing a positive organizational IT climate. Second, we illustrate the effect of an established IT climate on organizational output, such as strategic alignment and firm performance. And finally, through a multigroup analysis, we were able to identify differences for knowledgeintensive industries.

In general, out study confirms the hypothesis that CIO practices condition IT climate [62]. Referring to [8], the degree of already disseminated IT knowledge throughout the organization, namely TMT IT knowledge and firm IT knowledge, allows to draw conclusions about the existence of already established IT climates in the surveyed enterprises. Though, the results suggest the need to differentiate for the IT knowledge leadership: The impact of TMT IT knowledge on firm IT knowledge is very strong (H2). Even for knowledge-intensive organizations, our group comparison shows a significantly higher impact from the IT knowledge of business leaders to firm IT knowledge. The full mediation of $\mathrm{H} 3$ by the connection of TMT knowledge to the business employees' proposes the necessity to distinguish which employees are supposed to be followers of the CIO. The decreasing effect of the direct influence of CIO leadership to firm IT knowledge may be explained by referring to Mintzberg [39], who classified employees not as subordinates of the CIO, but as followers of the TMT, even in cases of IT issues. Referring to the concept of organizational climates as prescription of behavioral and attitudinal mindsets [62, 31, 20], we expect knowledge leaders to be legitimized and empowered by other C-level leaders [1]. The full mediation effect for $\mathrm{H} 3$ suggests, that this is not the case in our sample: The CIO leadership does not di- 
rectly influence firm IT knowledge. Thus, we conclude an IT climate yet as influencing the CEO's IT knowledge, but not being fully perceived by the employees as established by the CIO. Therefore, we advocate the CIO as to position as a business leader with adequate organizational standing, e.g., as board member with direct reporting to the CEO [13]. For the same reason, the results of this study suggest the CIO's involvement in the board as relevant for an expression of a close relationship between the CIO and the CEO [21] and a signal to high leadership qualities.

To broaden the view on the business leaders as well, we confirm senior executives as the most important agency to organizational knowledge creation (H2), consistent with [58], even for IT knowledge. Thus, we state the importance of business IT knowledge of the TMT to the whole organization (H1 $+\mathrm{H} 2)$ as CIO and TMT are likely to implement IT climate cooperatively. To ensure that business leaders possess sufficient IT knowledge, CIOs should be in possession of appropriate IT business knowledge and accompanying communication skills to transfer their IT knowledge to highlight the importance of IT [3]. An intensive relationship between CIOs and TMT signals a transformative IT vision as supposed by social alignment literature [47, 52, 33]. Moreover, a clear vision is key to setting IT climates as well [8].

As a result of this research, we recommend to constitute an organizational climate of knowledge sharing to enhance the motivation to exchange knowledge between providers (knowledge leader) and recipients (IS user) to increase IT performance [48]. In line, the presented construct of firm IT knowledge statistically outperforms very stable in our analysis due to the presented quality criteria. Thus, this discloses new perspectives for future research, as IS workflows and initiatives are determined knowledge-intensive, demanding specific IT skills by business users having the necessary IT knowledge [34]. To improve organizational IT capabilities, we recommend to support business-side employees more effectively by frequent IT knowledge transfer [18, 56]. The highly significant confirmation of $\mathrm{H} 6$ affirms the importance of mission-critical IT knowledge to business staff to organizational performance $[18,56]$.

Building our definition of IT climate on organizational climate as intangible organizational facets such as vision, knowledge sharing, and empowerment, we proved its impact on organizational outcomes [62], therefore mediated by strategic alignment. The significant group differences for $\mathrm{H} 2$ in combination with the stable relation from strategic alignment to firm performance suggest that knowledge-intensive organizations in our sample cope with the challenges of a knowledge-dominated competition [26, 7] by having established an adequate IT climate.

To contribute to business IT alignment literature, our results reconfirm extant findings on the influence of both business and IT to alignment (H4, H5) [54]. As strategic alignment leads to effective exploitation of IT resources which is in turn key competence of the CIO, CIO leadership in knowledge-intensive industries influences strategic alignment significantly higher, according to the results of the multigroup analysis. Especially through the dissemination of IT domain knowledge towards the TMT (H1), we underline the importance of social alignment as antecedent to strategic alignment (H4, H5). The influence of firm IT knowledge on strategic alignment (H6) was found significant and important to all industries to the same extent. The conducted group comparison emphasizes the general impact of strategic alignment on firm performance (H7) independent from the knowledge intensity of the industry type which reassures prior findings $[63,54]$. By the significance of $\mathrm{H} 4$ and $\mathrm{H} 7$, we confirmed the extant impact of CIO leadership qualities on firm performance, likewise measured in strategic market oriented parameters such as market share and sales revenue [13].

In this research, we explored as one of the first IT climate in organizations and confirmed its influence on strategic outcome in a quantitative research approach. We demonstrated first evidence to the existence, effects, and imperative of an IT climate capable of breaking the borders of the IT function and encompassing the whole organization. This will gain importance to both academia and practitioners as to the increasing IT saturation of almost each business process. Especially the previous qualitatively developed linkage from leadership to IT climate [62] was verified within our study by quantitative evidence, precisely demonstrating the joint responsibility of both business and IT leaders for an organization-wide IT climate. To intensify the leadership influence of the CIO on IT climate, it would be worth incorporating hierarchical properties of the CIO position such as the structural power of the CIO [13] to strengthen the employee's perceptions of the CIO as the knowledge leader for IT, particularly to knowledge and IT intensive industries. Future research should concentrate on adding more effects and linkages as well as forming dimensions to help expand the understanding of IT climate, e.g., through additive measures like IT skills, experience in IT, or perceived IT vision [49, 43]. In advance, qualitative interviews shall underpin relevant findings and maintain normative propositions for IT climate. Investigating organi- 
zational cultures such as organizational mindfulness and climate properties, as well as trust possibly bears potential to complete the picture of the adherence of IT and organizations. To supplement an operative level to this analysis on strategical constellations, influencing knowledge management structures could be integrated to a future research model to identify knowledge flows more deeply.

\section{References}

[1] Alavi, M., T.R. Kayworth, and D.E. Leidner, "An Empirical Examination of the Influence of Organizational Culture on Knowledge Management Practices", Journal of Management Information Systems, 22(3), 2006, pp. 191-224.

[2] Aral, S. and P. Weill, "IT Assets, Organizational Capabilities, and Firm Performance: How Resource Allocations and Organizational Differences Explain Performance Variation", Organization Science, 18(5), 2007, pp. 763-780.

[3] Armstrong, C.P. and V. Sambamurthy, "Information Technology Assimilation in Firms: The Influence of Senior Leadership and IT Infrastructures", Information Systems Research, 10(4), 1999, pp. 304-327.

[4] Banker, R.D., N. Hu, P.A. Pavlou, and J. Luftman, "CIO Reporting Structure, Strategic Positioning, and Firm Performance", MIS Quarterly, 35(2), 2011, pp. 487-504.

[5] Bassellier, G. and I. Benbasat, "Business Competence of Information Technology Professionals: Conceptual Development and Influence on IT-Business Partnerships", MIS Quarterly, 28(4), 2004, pp. 673-694.

[6] Bassellier, G., I. Benbasat, and B.H. Reich, "The Influence of Business Managers' IT Competence on Championing IT", Information Systems Research, 14(4), 2003, pp. 317-336.

[7] Bharadwaj, A.S., "A Resource-Based Perspective on Information Technology Capability and Firm Performance: An Empirical Investigation", MIS Quarterly, 24(1), 2000, pp. 169196.

[8] Boynton, A.C., R.W. Zmud, and G.C. Jacobs, "The Influence of IT Management Practice on IT Use in Large Organizations", MIS Quarterly, 18(3), 1994, pp. 299-318.

[9] Bullock, H.E., L.L. Harlow, and S.A. Mulaik, "Causation issues in structural equation modeling research", Structural Equation Modeling: A Multidisciplinary Journal, 1(3), 1994, pp. 253-267.

[10] Chan, Y.E., R. Sabherwal, and J.B. Thatcher, "Antecedents and outcomes of strategic IS alignment: An empirical investigation", IEEE Transactions on Engineering Management, 53(1), 2006, pp. 27-47.

[11] Chatterjeem, D., V.J. Richardson, and R.W. Zmud, "Examining the Shareholder Wealth Effects of Announcements of Newly Created CIO Positions", MIS Quarterly, 25(1), 2001, pp. 43-70.

[12] Chen, D.Q., M. Mocker, D.S. Preston, and A. Teubner, "Information systems strategy: reconceptualization, measurement, and implications", MIS Quarterly, 34(2), 2010, pp. 233 259.

[13] Chen, D.Q., D.S. Preston, and W. Xia, "Antecedents and Effects of CIO Supply-Side and Demand-Side Leadership: A Staged Maturity Model", Journal of Management Information Systems, 27(1), 2010, pp. 231-272.

[14] Chin, W.W., The Partial Least Square Approach to Structural Equation Modeling, Lawrence Erlbaum Associates, Mahwah, New Jersey, 1998.
[15] Collins, C.J. and K.G. Smith, "Knowledge Exchange and Combination: The Role of Human Resource Practices in the Performance of High Technology Firms", Academy of Management Journal, 49(3), 2006, pp. 544-560.

[16] Conner, K.R. and C.K. Prahalad, "A Resource-Based Theory of the Firm: Knowledge Versus Opportunism", Organization Science, 7(5), 1996, pp. 477-501.

[17] Croteau, A.-M. and L. Raymond, "Performance outcomes of strategic and IT competencies alignment", Journal of Information Technology, 19(3), 2004, pp. 178-190.

[18] Deng, X.N., T. Wang, and R.D. Galliers, "More than providing 'solutions': Towards an understanding of customeroriented citizenship behaviours of IS professionals", Information Systems Journal, 25(5), 2015, pp. 489-530.

[19] Dickson, M.W., D. Smith, M.W. Grojean, and M. Ehrhart, "An organizational climate regarding ethics: The outcome of leader values and the practices that reflect them", The Leadership Quarterly, 12(2), 2001, pp. 197-217.

[20] Durcikova, A., K.J. Fadel, B.S. Butler, and D.F. Galletta, "Research Note - Knowledge Exploration and Exploitation: The Impacts of Psychological Climate and Knowledge Management System Access", Information Systems Research, 22(4), 2011, pp. 855-866.

[21] Feeny, D.F., B.R. Edwards, and K.M. Simpson, "Understanding the CEO/CIO Relationship", MIS Quarterly, 16(4), 1992, pp. 435-448.

[22] Fornell, C. and D.F. Larcker, "Evaluating Structural Equation Models with Unobservable Variables and Measurement Error", Journal of Marketing Research, 18(1), 1981, pp. 39-50. [23] Gefen, D., D. Straub, and M.-C. Boudreau, "Structural equation modeling and regression: Guidelines for research practice", Communications of the Association for Information Systems, 4(1), 2000, pp. 1-77.

[24] Gerbing, D.W. and J.C. Anderson, "An Updated Paradigm for Scale Development Incorporating Unidimensionality and Its Assessment", Journal of Marketing Research, 25(2), 1988, pp. 186-192.

[25] Gerow, J.E., V. Grover, J. Thatcher, and P.L. Roth, "Looking Toward the Future of IT-Business Strategic Alignment through the Past: A Meta-Analysis", MIS Quarterly, 38(4), 2014, pp. 1159-1185.

[26] Grant, R.M., "The Resource-Based Theory of Competitive Advantage: Implications for Strategy Formulation", California Management Review, 33(3), 1991, pp. 114-135.

[27] Hair, J.F., A primer on partial least squares structural equations modeling (PLS-SEM), SAGE, Los Angeles, 2014.

[28] Henderson, J.C. and H. Venkatraman, "Strategic alignment: Leveraging information technology for transforming organizations", IBM Systems Journal, 32(1), 1993, pp. 472484.

[29] Henseler, J., C.M. Ringle, and R.R. Sinkovics, Advances in International Marketing, Emerald Group Publishing, Bingley, 2009.

[30] Hofstede, G., "Identifying Organizational Subcultures: An Empirical Approach", Journal of Management Studies, 35(1), 1998, pp. 1-12.

[31] James, L.R., C.C. Choi, C.-H.E. Ko, P.K. McNeil, M.K. Minton, M.A. Wright, and K.-i. Kim, "Organizational and psychological climate: A review of theory and research", European Journal of Work and Organizational Psychology, 17(1), 2008, pp. 5-32.

[32] Karahanna, E. and D.S. Preston, "The Effect of Social Capital of the Relationship Between the CIO and Top Management Team on Firm Performance", Journal of Management Information Systems, 30(1), 2013, pp. 15-56. 
[33] Kearns, G.S. and R. Sabherwal, "Strategic Alignment Between Business and Information Technology: A Knowledge-Based View of Behaviors, Outcome, and Consequences", Journal of Management Information Systems, 23(3), 2007, pp. 129-162.

[34] King, W.R. and T.S. Teo, "Integration Between Business Planning and Information Systems Planning: Validating a Stage Hypothesis", Decision Sciences, 28(2), 1997, pp. 279308.

[35] Krogh, G. von, I. Nonaka, and L. Rechsteiner, "Leadership in Organizational Knowledge Creation: A Review and Framework", Journal of Management Studies, 49(1), 2012, pp. 240-277.

[36] Lewin, K., "Group decision and social change", Readings in social psychology, 3, 1947, pp. 197-211.

[37] Lindgren, R., O. Henfridsson, and U. Schultze, "Design Principles for Competence Management Systems: A Synthesis of an Action Research Study", MIS Quarterly, 28(3), 2004, pp. 435-472.

[38] Lu, Y. and K. Ramamurthy, "Understanding the Link Between Information Technology Capability and Organizational Agility: An Empirical Examination", MIS Quarterly, 35(4), 2011, pp. 931-954.

[39] Mintzberg, H., The nature of managerial work, Harper \& Row, New York, USA, 1973.

[40] Nonaka, I., "A Dynamic Theory of Organizational Knowledge Creation", Organization Science, 5(1), 1994, pp. 14-37.

[41] Nunnally, J., Psychometric Theory, 2nd edn., Grow-Hill, New York, 1978.

[42] OECD, OECD Science, Technology and Industry Scoreboard 2013, Organization for Economic Cooperation \& Development, Paris, Washington, 2013.

[43] Peppard, J. and J. Ward, "Beyond strategic information systems: Towards an IS capability", The Journal of Strategic Information Systems, 13(2), 2004, pp. 167-194.

[44] Podsakoff, P.M., S.B. MacKenzie, J.-Y. Lee, and N.P. Podsakoff, "Common method biases in behavioral research: A critical review of the literature and recommended remedies", Journal of Applied Psychology, 88(5), 2003, pp. 879-903.

[45] Preacher, K.J. and A.F. Hayes, "Asymptotic and resampling strategies for assessing and comparing indirect effects in multiple mediator models", Behavior Research Methods, 40(3), 2008, pp. 879-891.

[46] Preston, D.S., D. Chen, and D.E. Leidner, "Examining the Antecedents and Consequences of CIO Strategic DecisionMaking Authority: An Empirical Study", Decision Sciences, 39(4), 2008, pp. 605-642.

[47] Preston, D.S. and E. Karahanna, "Antecedents of IS Strategic Alignment: A Nomological Network", Information Systems Research, 20(2), 2009, pp. 159-179.

[48] Quigley, N.R., P.E. Tesluk, E.A. Locke, and K.M. Bartol, "A Multilevel Investigation of the Motivational Mechanisms Underlying Knowledge Sharing and Performance", Organization Science, 18(1), 2007, pp. 71-88.

[49] Ravichandran, T. and C. Lertwongsatten, "Effect of Information Systems Resources and Capabilities on Firm Performance: A Resource-Based Perspective", Journal of Management Information Systems, 21(4), 2005, pp. 237-276.

[50] Ravishankar, M.N., S.L. Pan, and D.E. Leidner, "Examining the Strategic Alignment and Implementation Success of a KMS: A Subculture-Based Multilevel Analysis", Information Systems Research, 22(1), 2011, pp. 39-59.
[51] Reich, B.H. and I. Benbasat, "Measuring the Linkage between Business and Information Technology Objectives", MIS Quarterly, 20(1), 1996, pp. 55-81.

[52] Reich, B.H. and I. Benbasat, "Factors That Influence the Social Dimension of Alignment between Business and Information Technology Objectives", MIS Quarterly, 24(1), 2000, pp. 81-113.

[53] Ringle, C.M., S. Wende, and J.-M. Becker, "SmartPLS 3.2.3", SmartPLS GmbH, Boenningstedt, 2015.

[54] Sabherwal, R. and Y.E. Chan, "Alignment Between Business and IS Strategies: A Study of Prospectors, Analyzers, and Defenders", Information Systems Research, 12(1), 2001, pp. 11-33.

[55] Sackmann, S.A., "Culture and subcultures: An analysis of organizational knowledge", Administrative Science Quarterly, 37(1), 1992, pp. 140-161.

[56] Santhanam, R., L. Seligman, and D. Kang, "Postimplementation Knowledge Transfers to Users and Information Technology Professionals", Journal of Management Information Systems, 24(1), 2007, pp. 171-199.

[57] Sarstedt, M., J. Henseler, and C.M. Ringle, "Multigroup Analysis in Partial Least Squares (PLS) Path Modeling: Alternative Methods and Empirical Results", in Measurement and Research Methods in International Marketing, M. Sarstedt, M. Schwaiger, and C.R. Taylor, Editors. 2011. Emerald Group Publishing Limited.

[58] Škerlavaj, M., V. Dimovski, and K.C. Desouza, "Patterns and structures of intra-organizational learning networks within a knowledge-intensive organization", Journal of Information Technology, 25(2), 2010, pp. 189-204.

[59] Starbuck, W.H., "Learning by knowledge-intensive firms", Journal of Management Studies, 29(6), 1992, pp. 713740.

[60] Tsoukas, H. and E. Vladimirou, "What is Organizational Knowledge?", Journal of Management Studies, 38(7), 2001, pp. 973-993.

[61] Van de Ven, A.H., "Running in Packs to Develop Knowledge-Intensive Technologies", MIS Quarterly, 29(2), 2005, pp. 365-377.

[62] Watts, S. and J.C. Henderson, "Innovative IT climates: CIO perspectives", The Journal of Strategic Information Systems, 15(2), 2006, pp. 125-151.

[63] Wu, S.P.-J., D.W. Straub, and T. Liang, "How information technology governance mechanisms and strategic alignment influence organizational performance: Insights from a matched survey of business and IT managers", MIS Quarterly, 39(2), 2015, pp. 497-518. 